\title{
Best Albuminuria Measurement to Predict Cardiovascular and Renal Events
}

\author{
Lucie Bauer $^{\mathrm{a}}$ Insa E. Emrich ${ }^{\mathrm{a}}$ John W. Pickering ${ }^{\mathrm{b}, \mathrm{c}}$ Kathrin Untersteller ${ }^{\mathrm{a}}$ \\ Franziska Sandermann ${ }^{a}$ Kyrill S. Rogacev ${ }^{a}$ Sarah Seiler-Mussler ${ }^{a}$ \\ Danilo Fliser $^{\mathrm{a}}$ Gunnar H. Heine ${ }^{\mathrm{a}}$ \\ a Internal Medicine IV - Nephrology and Hypertension, Saarland University Medical Center, Homburg, Germany; \\ ${ }^{b}$ Department of Medicine, University of Otago Christchurch, and ${ }^{\mathrm{C} D e p a r t m e n t ~ o f ~ E m e r g e n c y, ~ C h r i s t c h u r c h ~ H o s p i t a l, ~}$ \\ Christchurch, New Zealand
}

\section{Key Words}

Albuminuria $\cdot$ Cardiovascular $\cdot$ Epidemiology $\cdot$ Chronic

kidney disease

\begin{abstract}
Background: Kidney Disease Improving Global Outcomes (KDIGO) guidelines encourage clinicians to estimate 24-hour albuminuria as albumin to creatinine ratio (ACR) from spot urine samples. However, ACR underestimates 24-hour albumin excretion in muscular individuals. Equations that adjust ACR for surrogates of muscle mass to yield an estimated albumin excretion rate (eAER) were developed. We hypothesised that eAER is a better predictor of cardiovascular and renal outcomes than ACR. Methods: We determined ACR and eAER among 443 patients with chronic kidney disease G2-G4 recruited into the CARE FOR HOMe study. Patients were classified into KDIGO albuminuria categories, and followed for cardiovascular and renal events. The primary analysis was the net reclassification improvement (NRI) for those with and without events within 3 years of follow-up. Results: Eighty five patients experienced cardiovascular events during 3 years of follow-up, 13 of whom were reclassified to a more advanced albuminuria category, and 1 patient to a less
\end{abstract}

advanced category by eAER compared to ACR (NRI event: : $14.1 \%$ (95\% Cl 5.8-22.4)). Among 358 patients without a cardiovascular event, 17 patients were reclassified to a more advanced albuminuria category, and 2 patients to a less advanced category by eAER ( $\mathrm{NRI}_{\text {no event }}:-4.2 \%, 95 \% \mathrm{Cl}-8.5$ to -1.8 ). Sixty patients went through renal events, and 383 patients had event-free 3-year follow-up. $\mathrm{NRI}_{\text {event }}$ was $6.7 \%$ $(95 \% \mathrm{Cl}-1.2$ to 14.5$)$, and $\mathrm{NRI}_{\text {no event }}$ was $-6.0 \%(95 \% \mathrm{Cl}-10.6$ to 3.4) for renal events. Conclusion: Compared to ACR albuminuria categories, eAER categories are better associated with future cardiovascular events, but not with renal events.

(c) 2016 S. Karger AG, Basel

\section{Introduction}

Accurate quantification of albuminuria in patients with chronic kidney disease (CKD) is necessary to risk stratify patients for renal and cardiovascular outcomes and guide clinical management. Current Kidney Disease Improving Global Outcomes (KDIGO) guidelines recommend the assessment of albuminuria as the albumin to creatinine ratio (ACR) from early morning urine samples, since ACR is not inferior to the gold standard of 24-

\section{KARGER}

E-Mail karger@karger.com

www.karger.com/ajn
(C) 2016 S. Karger AG, Basel

$0250-8095 / 16 / 0435-0383 \$ 39.50 / 0$ 
hour urine collection for prediction of adverse renal and cardiovascular outcome and 24-hour urine collection is considered too cumbersome in clinical practice [1].

Therefore, KDIGO equates albuminuria per gram creatinine with albuminuria per 24-hour, assuming a daily creatinine excretion of $1,000 \mathrm{mg}$ for each patient. This method ignores relevant inter-individual differences, as creatinine excretion is higher in persons with higher muscle mass, which itself is associated with younger age, male gender and African American ethnicity. Consequently, ACR will inevitably underestimate albuminuria in young muscular men and vice versa overestimate albuminuria in older women with lower muscle mass [2-4].

Recently, equations were developed which adjust ACR for surrogates of muscle mass, namely, gender, age and ethnicity, and yield an estimated albumin excretion rate (eAER). It has been shown in cross-sectional studies that eAER better reflects 24-hour albuminuria than ACR [2, $3]$. It follows that, in clinical practice, eAER could be substituted for ACR to categorise patients [2]. A direct comparison of the predictive performance for adverse outcomes between eAER and ACR has not been performed. Therefore, we aimed to determine if substituting eAER for ACR better risk stratifies CKD patients for adverse renal and cardiovascular outcome.

\section{Material and Methods}

The CARE FOR HOMe study is an ongoing prospective cohort study of patients with CKD G2-G4 (estimated glomerular filtration rate (eGFR) $15-89 \mathrm{ml} / \mathrm{min} / 1.73 \mathrm{~m}^{2}$ by the MDRD equation [1]) at baseline. All patients are under regular nephrological care at the outpatient department of Saarland University Medical Center, Homburg, Germany.

Our study excluded transplant recipients, pregnant women, patients $<18$ years of age, patients under systemic immunosuppressive medication, patients with HIV infection, with clinically apparent infections (defined as C-reactive protein (CRP) levels $>50 \mathrm{mg} / \mathrm{l}$, and/or requiring systemic antibiotic therapy), with active malignancy or with acute kidney injury (defined as increase of plasma creatinine $>50 \%$ within the preceding 4 weeks). The study protocol was approved by the local Ethics Committee; all patients gave written consent.

At baseline, fasting blood samples for standard laboratory measurements, GFR estimation, and a spot urine sample were collected. This spot urine sample in general corresponded to the second morning urine sample taken between 7 a.m. and 11 a.m. when all patients presented to the outpatient department.

Information on co-morbidities, cardiovascular risk factors and medication was gathered from chart review and a standardized questionnaire.

Prevalent cardiovascular disease (CVD) was defined as a history of myocardial infarction, coronary artery angioplasty/stent- ing/bypass surgery, major stroke, carotid endarterectomy/stenting, nontraumatic lower extremity amputation or lower limb artery angioplasty/stenting/bypass surgery.

Patients were categorised as active smokers if they were current smokers or had stopped smoking less than 1 month before entry into the study. Patients with self-reported or physician-reported diabetes mellitus, with a fasting blood glucose level of $>126 \mathrm{mg} / \mathrm{dl}$ and/or with current use of hypoglycaemic medication, were categorised as diabetics [5].

From baseline morning spot urine sample, we measured urine albumin (immunonephelometric BN II/BN assay, Siemens, Marburg, Germany) and urine creatinine (Jaffé method, COBAS, Mannheim, Germany). We calculated ACR as the ratio of urine albumin to urine creatinine [1]. To determine eAER, we multiplied ACR with the estimated creatinine excretion rate (eCER), which was calculated according to the Ellam equation [2]:

$$
\begin{aligned}
\mathrm{eCER}_{\text {Ellam }}(\mathrm{mg} / \text { day }) & =1,413.9+(23.2 \times \text { age })-\left(0.3 \times \mathrm{age}^{2}\right) \text { in } \\
& \text { black men } \\
& =1,148.6+(15.6 \times \text { age })-\left(0.3 \times \mathrm{age}^{2}\right) \text { in } \\
& \text { black women } \\
& =1,307.3+(23.1 \times \text { age })-\left(0.3 \times \mathrm{age}^{2}\right) \text { in } \\
& \text { nonblack men } \\
& =1,051.3+(5.3 \times \text { age })-\left(0.1 \times \text { age }^{2}\right) \text { in } \\
& \text { nonblack women }
\end{aligned}
$$

Among 3 different equations for eCER, we decided a priori to focus our analyses upon the Ellam equation, which is most suitable for automatic calculation and reporting by laboratories, requiring only age, gender and ethnicity. A secondary analysis made use of the Ix et al. [6] and Walser [7] equations (online suppl. table S1; for all online suppl. material, see www.karger. com/doi/10.1159/000446483), which additionally require body weight for eCER calculation. All patients were classified to KDIGO albuminuria categories: A1: <30; A2: 30-300; A3: $>300$ $\mathrm{mg} / \mathrm{g}$ creatinine.

We invited all patients annually to the study centre, where we collected clinical information on cardiovascular outcome, and determined follow-up eGFR. In case a patient did not attend this annual visit, we performed a standardised telephone interview, and obtained information on creatinine values from the treating primary-care physician.

We focused our analyses on the first 444 CARE FOR HOMe participants, who had been recruited between 2008 and 2012, as these patients had complete 3 -year follow-up information in December 2015. One single patient did not provide a baseline urinary sample; therefore, 443 patients were included into the subsequent analyses. Patients who had been recruited after 2012 are not analysed in this report.

The cardiovascular primary endpoint was myocardial infarction, coronary artery angioplasty/stenting/bypass surgery, major stroke, carotid endarterectomy/stenting, nontraumatic lower extremity amputation, lower limb artery angioplasty/stenting/bypass surgery, or death of any cause. The renal primary endpoint was the combination of either need for renal replacement therapy (RRT), halving of eGFR, or death of any cause. For definition of renal outcome, we did not consider intermittent need for RRT or a transient decline of eGFR with subsequent renal function recovery as renal events. 
Cardiovascular and renal outcome adjudication was done by 2 independent physicians, who were blinded for baseline data. In case of disagreement, a third physician was consulted.

Statistical Analyses

Categorical variables are presented as a percentage of patients and compared using the Fisher test. Continuous data are expressed as means $\pm \mathrm{SD}$, and were compared using a t test for 2 independent samples (albuminuria and CRP are presented as median (interquartile range) because of skewed distribution, and compared by the Mann-Whitney U test).

We assessed the predictive performance of albuminuria and eAER by univariate Cox regression analysis for the first event during the complete follow-up and by calculating the area under the receiver operator characteristic curve (AUC) for patients with and without cardiovascular and renal events during the first 3 years of follow-up. We first logged albuminuria (base 10) because it was non-normal distributed, and then reported hazard ratios (HRs) per unit increase in log albuminuria.

Risk category reclassification by eAER was assessed by the net reclassification improvement (NRI) metric $[8,9]$. We report the NRI separately for those with and without events during the first years of follow-up, as the meaningfulness of the overall NRI has been questioned [10]. All calculations were made in R [11] using the rap package [12].

\section{Results}

Baseline characteristics of the 443 CARE FOR HOMe participants are presented in table 1 . The mean age of the entire cohort was $65 \pm 12$ at baseline, mean eGFR was $45 \pm 16 \mathrm{ml} / \mathrm{min} / 1.73 \mathrm{~m}^{2}$, and 179 (40\%) participants were female.

\section{Cardiovascular Events}

Thirty patients were reclassified to a more advanced albuminuria category when substituting eAER for ACR, and only 3 patients were reclassified to a less advanced category (table 2). As expected, male and younger patients were more likely to be reclassified to a more advanced albuminuria category than female and older patients (online suppl. table S2).

The HRs and AUCs were almost identical for ACR and eAER (table 3).

Eighty five patients reached the predefined cardiovascular endpoint; these patients were older, had lower diastolic blood pressure (BP) measurements and lower cholesterol at baseline than patients who did not undergo any cardiovascular events (online suppl. table S3). Moreover, they had higher albuminuria and a higher prevalence of CVD and diabetes mellitus.

Among these 85 patients who reached the cardiovascular endpoint, 13 were reclassified to a more advanced
Table 1. Baseline characteristics of CARE FOR HOMe study participants

Total cohort $(n=443)$
Age, years

Gender, female, n (\%)

eGFR, $\mathrm{ml} / \mathrm{min} / 1.73 \mathrm{~m}^{2}$

BMI, $\mathrm{kg} / \mathrm{m}^{2}$

Diabetes mellitus (yes), $\mathrm{n}(\%)$

Systolic BP, mm Hg

Diastolic BP, mm Hg

Smoking (yes), n (\%)

Prevalent CVD (yes), n (\%)

LDL-C, mg/dl

Cholesterol, mg/dl

Phosphorus, $\mathrm{mg} / \mathrm{dl}$

Albuminuria, $\mathrm{mg} / \mathrm{g}$

CRP, mg/l

Caucasian ethnicity, $\mathrm{n}(\%)$

Afroamerican ethnicity, n (\%)

$65 \pm 12$
$179(40)$
$45 \pm 16$
$30 \pm 6$
$167(38)$
$154 \pm 24$
$87 \pm 13$
$44(10)$
$137(31)$
$116 \pm 36$
$193 \pm 42$
$3.4 \pm 0.7$
$36(8-193)$
$2.7(1.2-5.3)$
$441(99)$
$2(1)$

Indicated are means $\pm \mathrm{SD}$, or patient numbers (percentages), as appropriate. Because of skewed distribution, albuminuria and $\mathrm{CRP}$ are given as median (interquartile range). $\mathrm{BMI}=$ Body mass index; LDL-C = low density lipoprotein-cholesterol. albuminuria category when substituting eAER for ACR. Only 1 patient was reclassified to a less advanced category, and 71 patients stayed in the same category, yielding an $\mathrm{NRI}_{\text {event }}$ of $14.1 \%$ (95\% CI 5.8-22.4; table 2).

Of the 358 patients who did not experience a cardiovascular event, 17 patients moved to a more advanced albuminuria category, 2 patients moved to a less advanced albuminuria category, and 339 patients stayed in the same category, resulting in an $\mathrm{NRI}_{\text {no event }}$ of $-4.2 \%$ (95\% CI -8.5 to -1.8 ; table 2 ).

Reclassification therefore decreased the proportion of events in category A1 and increased them in A2; however, there was little change to the proportion of events in A3 (online suppl. fig. S1).

\section{Renal Events}

Sixty patients had a primary renal event (online suppl. table S4), of whom 32 patients reached ESRD, 1 patient had GFR without reaching ESRD and 27 patients died without halving of GFR and/or reaching ESRD. The HRs and AUCs were almost identical for ACR and eAER (table 3).

Of patients with events, 5 moved to a more advanced albuminuria category, one to a less advanced category and 54 stayed in the same category, which leads to an $\mathrm{NRI}_{\text {event }}$ $6.7 \%$ (95\% CI -1.2 to 14.5 ; table 4$)$. Three hundred and 
Table 2. Reclassification matrices for CARE FOR HOMe participants with and without cardiovascular events (applying Ellam equation for eAER)

\begin{tabular}{|c|c|c|c|c|c|c|}
\hline \multirow{2}{*}{$\begin{array}{l}\text { ACR, } \\
\text { n (\%) }\end{array}$} & \multicolumn{3}{|c|}{ eAER: events $(n=85), \%$} & \multicolumn{3}{|c|}{ eAER: no events $(\mathrm{n}=358), \%$} \\
\hline & A1 & A2 & A3 & A1 & A2 & A3 \\
\hline A1 & $22(25.9)$ & $10(11.8)$ & 0 & $171(47.8)$ & $8(2.2)$ & 0 \\
\hline $\mathrm{A} 2$ & 0 & $28(32.9)$ & $3(3.5)$ & $2(0.6)$ & $101(28.2)$ & $9(2.5)$ \\
\hline \multirow[t]{2}{*}{$\mathrm{A} 3$} & 0 & $1(1.2)$ & $21(24.7)$ & 0 & 0 & $67(18.7)$ \\
\hline & \multicolumn{3}{|c|}{$\mathrm{NRI}_{\text {event }}=14.1(5.8-22.4)$} & \multicolumn{3}{|c|}{$\mathrm{NRI}_{\text {no event }}=-4.2(-8.5$ to -1.8$)$} \\
\hline
\end{tabular}

Given are A1: <30; A2: 30-300; A3: >300 mg/g creatinine. 95\% CIs are shown in brackets.

Table 3. HRs and AUCs for cardiovascular and renal outcomes

\begin{tabular}{lll}
\hline & ACR & eAER \\
\hline Cardiovascular events & & \\
$\quad$ HR & $1.49(1.23-1.80)$ & $1.46(1.21-1.75)$ \\
AUC & $0.60(0.53-0.66)$ & $0.59(0.53-0.65)$ \\
Renal events & & \\
HR & $2.33(1.89-2.87)$ & $2.25(1.83-2.76)$ \\
AUC & $0.71(0.64-0.78)$ & $0.71(0.64-0.78)$ \\
\hline
\end{tabular}

HR (per unit increase in $\log _{10}$ ACR and eAER) respectively in univariate Cox regression analysis.

Table 4. Reclassification matrices for CARE FOR HOMe participants with and without renal events (applying Ellam equation for eAER)

\begin{tabular}{|c|c|c|c|c|c|c|}
\hline \multirow{2}{*}{$\begin{array}{l}\text { ACR, } \\
\text { n (\%) }\end{array}$} & \multicolumn{3}{|c|}{ eAER: events $(n=60), \%$} & \multicolumn{3}{|c|}{ eAER: no events $(n=383), \%$} \\
\hline & A1 & $\mathrm{A} 2$ & A3 & A1 & A2 & A3 \\
\hline A1 & $10(16.7)$ & $3(5.0)$ & 0 & $183(47.8)$ & $15(3.9)$ & 0 \\
\hline $\mathrm{A} 2$ & 0 & $20(33.3)$ & $2(3.3)$ & $2(0.5)$ & $109(28.5)$ & $10(2.6)$ \\
\hline \multirow[t]{2}{*}{ A3 } & 0 & $1(1.7)$ & $24(40.0)$ & 0 & 0 & $64(16.7)$ \\
\hline & \multicolumn{3}{|c|}{$\mathrm{NRI}_{\text {event }}=6.7(-1.2$ to 14.5$)$} & \multicolumn{3}{|c|}{$\mathrm{NRI}_{\text {no event }}=-6.0(-10.6$ to 3.4$)$} \\
\hline
\end{tabular}

$\mathrm{A1}:<30 ; \mathrm{A} 2: 30-300 ; \mathrm{A} 3:>300 \mathrm{mg} / \mathrm{g}$ creatinine. $95 \% \mathrm{CI}$ are shown in brackets.

eighty three patients did not experience a renal event. Of these, 25 patients were reclassified to a more advanced albuminuria category, 2 to a less advanced category and 356 patients stayed in the same category, which resulted in an $\mathrm{NRI}_{\text {no event }}-6.0 \%$ (95\% CI -10.6 to 3.4 ; table 4$)$.

The Ix and the Walser equations, which - unlike the Ellam equation - incorporate information on body weight results (online suppl. table S1) reclassified patients similarly to the Ellam equation in exploratory analyses.

\section{Discussion}

Substituting eAER for ACR improved risk classification of cardiovascular, but not of renal events. A net $14.1 \%$ of patients who went on to have a cardiovascular event were classified to higher albuminuria risk categories by eAER than ACR. While this was at the cost of $4.2 \%$ of those without a cardiovascular event also being reclassified to a higher risk category, this is a rea- 
sonable cost to pay to better identify those at greater risk.

We found no prognostic gain for renal outcome prediction: while a net $6.7 \%$ of those who went on to have a renal event were reclassified to a higher risk category, so were $6.0 \%$ of those who did not have an event.

In contrast to NRI analyses, Cox regression models and AUCs for cardiovascular outcome prediction yielded no substantially differences between eAER and ACR. We consider the findings from NRI analyses to be more pertinent, as treatment guidelines [1,13-15] refer to albuminuria categories, upon which NRI analyses are based.

Estimation of albuminuria is used to determine treatment strategies in CKD; for example, for adjusting $\mathrm{BP}$ targets $[16,17]$. The use of eAER instead of ACR to classify patients to albuminuria categories may increase the proportion of patients with more aggressive BP targets. It is unknown whether this would reduce cardiovascular events, or delay renal events. Subgroup analysis of the MDRD [18] and AASK [19] studies suggest that patients with high baseline albuminuria particularly benefited from aggressive BP targeting. Of note, in both studies, renal protein excretion was quantified from 24 -hour collections. As the application of ACR from spot urine samples will substantially underestimate albuminuria particularly in young males, a substantial patient group may be deprived from the benefits of intensive BP treatment if 24hour urine collections and ACR estimation are erroneously equated.

In our study design, we decided a priori to include death of any cause to both the primary cardiovascular and renal study endpoints. It may be argued that such an approach will dilute our analyses. However, exploratory analyses, in which non-renal death was not considered a renal event, and non-cardiovascular death was not considered a cardiovascular event, yielded similar results (data not shown).

Our study has some limitations: first, our primary analysis is based on our choice of eAER estimating equation. We deliberately chose the Ellam equation, which is the most suitable equation for automatic calculation and reporting by laboratories because it is based only on age, gender and ethnicity. Other eAER equations have been published $[6,7]$. These require body weight, which is seldom reported to laboratories. In exploratory analyses, we found that these equations $[6,7]$ yield similar findings (online suppl. tables S5-S8).

Second, CARE FOR HOMe is a single-centre, medium-size European cohort study, which recruits a Caucasian population referred to nephrologists, while the
Ellam equation was developed and externally validated among North American patients. Thus, confirmation of our study results in larger and non-European CKD cohorts, as well as in general population cohorts, is needed.

Third, we measured albuminuria only from a single spot urine sample at baseline and did not confirm our measurement with a second sample.

Finally, we cannot prove that the better cardiovascular risk prediction by eAER in comparison to ACR is fully explained by its more precise estimation of 24 -hour albuminuria. Instead, it may partly be caused by non-renal determinants of the eAER, particularly by the male gender and age. Compared to women, men have more frequently higher estimates for 24-hour albuminuria with eAER than with ACR, as the Ellam equation for the eCER has greater weightings for men than for women. Vice versa, older age lowers the eCER. Thus, conventional cardiovascular risk factors - male gender and age - have opposing effects on eAER.

In summary, albuminuria categorisation by eAER better risk stratifies for cardiovascular events, but not renal events, than ACR. The actual clinical benefit of eAER compared with ACR needs to be determined in further studies.

\section{Acknowledgements}

We thank Esther Herath, Anja Weihrauch, Franziska Flügge and Pagah Shaffein for their contributions to patient recruitment, and Marie-Therese Blinn, Martina Wagner, Annette Offenhäusser, Dagmar Kolb and Renate Schindler for excellent technical assistance.

\section{Disclosure Statement}

We have no conflicts of interest to declare. The CARE FOR HOMe study was supported by a grant from the Else-Kröner-Fresenius Stiftung.

References

1 KDIGO 2012 clinical practice guideline for the evaluation and management of chronic kidney disease. Kidney Int Suppl 2013;3:1150.

2 Fotheringham J, Campbell MJ, Fogarty DG, El Nahas M, Ellam T: Estimated albumin excretion rate versus urine albumin-creatinine ratio for the estimation of measured albumin excretion rate: derivation and validation of an estimated albumin excretion rate equation. Am J Kidney Dis 2014;63:405-414. 
3 Abdelmalek JA, Gansevoort RT, Lambers Heerspink HJ, Ix JH, Rifkin DE: Estimated albumin excretion rate versus urine albumincreatinine ratio for the assessment of albuminuria: a diagnostic test study from the prevention of renal and vascular end-stage disease (prevend) study. Am J Kidney Dis 2014;63:415-421.

4 Inker LA: Albuminuria: time to focus on accuracy. Am J Kidney Dis 2014;63:378-381.

5 Rogacev KS, Pickering JW, Seiler S, Zawada AM, Emrich I, Fliser D, Heine GH: The chronic kidney disease epidemiology collaboration (CKD-EPI) equation incorporating both cystatin $\mathrm{C}$ and creatinine best predicts individual risk: a cohort study in 444 patients with chronic kidney disease. Nephrol Dial Transplant 2014;29:348-355.

6 Ix JH, Wassel CL, Stevens LA, Beck GJ, Froissart M, Navis G, Rodby R, Torres VE, Zhang YL, Greene T, Levey AS: Equations to estimate creatinine excretion rate: the CKD epidemiology collaboration. Clin J Am Soc Nephrol 2011;6:184-191.

7 Walser M: Creatinine excretion as a measure of protein nutrition in adults of varying age. JPEN J Parenter Enteral Nutr 1987;11(5 suppl):73S-78S

8 Pencina MJ, D'Agostino RB Sr, D'Agostino RB Jr, Vasan RS: Evaluating the added predictive ability of a new marker: from area under the roc curve to reclassification and beyond. Stat Med 2008;27:157-172; discussion 207212.

9 Pickering JW, Endre ZH: New metrics for assessing diagnostic potential of candidate biomarkers. Clin J Am Soc Nephrol 2012;7: 1355-1364.

10 Leening MJ, Vedder MM, Witteman JC, Pencina MJ, Steyerberg EW: Net reclassification improvement: computation, interpretation, and controversies: a literature review and clinician's guide. Ann Intern Med 2014;160 122-131.
11 Team RC: R: a language and environment for statistical computing, 2014. http://www. R-project.Org/.

12 Pickering JW, Endre ZH, Cairns DA: Rap: an $\mathrm{R}$ package for reclassification metrics and risk assessment plots, 2014. https://www. Researchgate.Net/publication/268805453 rap_an_r_package_for_reclassification metrics_and_risk_assessment_plots.

13 Mancia G, Fagard R, Narkiewicz K, Redon J, Zanchetti A, Bohm M, Christiaens T, Cifkova R, De Backer G, Dominiczak A, Galderisi M, Grobbee DE, Jaarsma T, Kirchhof P, Kjeldsen SE, Laurent S, Manolis AJ, Nilsson PM, Ruilope LM, Schmieder RE, Sirnes PA, Sleight P, Viigimaa M, Waeber B, Zannad F, Redon J, Dominiczak A, Narkiewicz K, Nilsson PM, Burnier M, Viigimaa M, Ambrosioni E, Caufield M, Coca A, Olsen MH, Schmieder RE, Tsioufis C, van de Borne P, Zamorano JL, Achenbach S, Baumgartner H, Bax JJ, Bueno H, Dean V, Deaton C, Erol C, Fagard R, Ferrari R, Hasdai D, Hoes AW, Kirchhof P, Knuuti J, Kolh P, Lancellotti P, Linhart A, Nihoyannopoulos P, Piepoli MF, Ponikowski P, Sirnes PA, Tamargo JL, Tendera M, Torbicki A, Wijns W, Windecker S, Clement DL, Coca A, Gillebert TC, Tendera M, Rosei EA, Ambrosioni E, Anker SD, Bauersachs J, Hitij JB, Caulfield M, De Buyzere M, De Geest S, Derumeaux GA, Erdine S, Farsang C, FunckBrentano C, Gerc V, Germano G, Gielen S, Haller H, Hoes AW, Jordan J, Kahan T, Komajda $\mathrm{M}$, Lovic D, Mahrholdt $\mathrm{H}$, Olsen $\mathrm{MH}$, Ostergren J, Parati G, Perk J, Polonia J, Popescu BA, Reiner Z, Ryden L, Sirenko Y, Stanton A, Struijker-Boudier H, Tsioufis C, van de Borne P, Vlachopoulos C, Volpe M, Wood DA: $2013 \mathrm{ESH} / \mathrm{ESC}$ guidelines for the management of arterial hypertension: the task force for the management of arterial hypertension of the European society of hypertension (ESH) and of the European society of cardiology (ESC). Eur Heart J 2013;34:21592219.
14 Agarwal R: Hypertension: KDIGO BP guidelines - more individualized, less prescriptive. Nat Rev Nephrol 2013;9:131-133.

15 National Institute for Health and Care Excellence: Chronic kidney disease in adults: assessment and management, clinical guideline 182, 2014. http://guidance.nice.org.uk/CG182.

16 Gansevoort RT, Correa-Rotter R, Hemmelgarn BR, Jafar TH, Heerspink HJ, Mann JF, Matsushita K, Wen CP: Chronic kidney disease and cardiovascular risk: epidemiology, mechanisms, and prevention. Lancet 2013; 382:339-352.

17 Mancia G, Fagard R, Narkiewicz K, Redon J, Zanchetti A, Bohm M, Christiaens T, Cifkova R, De Backer G, Dominiczak A, Galderisi M, Grobbee DE, Jaarsma T, Kirchhof P, Kjeldsen SE, Laurent S, Manolis AJ, Nilsson PM, Ruilope LM, Schmieder RE, Sirnes PA, Sleight P, Viigimaa M, Waeber B, Zannad F; Task Force Members: 2013 ESH/ESC guidelines for the management of arterial hypertension: the task force for the management of arterial hypertension of the European society of hypertension (ESH) and of the European society of cardiology (ESC). J Hypertens 2013;31:1281-1357.

18 Peterson JC, Adler S, Burkart JM, Greene T, Hebert LA, Hunsicker LG, King AJ, Klahr S, Massry SG, Seifter JL: Blood pressure control, proteinuria, and the progression of renal disease. The modification of diet in renal disease study. Ann Intern Med 1995;123:754-762.

19 Appel LJ, Wright JT Jr, Greene T, Agodoa LY, Astor BC, Bakris GL, Cleveland WH, Charleston J, Contreras G, Faulkner ML, Gabbai FB, Gassman JJ, Hebert LA, Jamerson KA, Kopple JD, Kusek JW, Lash JP, Lea JP, Lewis JB, Lipkowitz MS, Massry SG, Miller ER, Norris K, Phillips RA, Pogue VA, Randall OS, Rostand SG, Smogorzewski MJ, Toto RD, Wang X; AASK Collaborative Research Group: Intensive blood-pressure control in hypertensive chronic kidney disease. N Engl J Med 2010; 363:918-929. 